\title{
Prevention of shoulder injuries in overhead athletes: a science-based approach
}

Ann M. Cools ${ }^{1}$, Fredrik R. Johansson ${ }^{1}$, Dorien Borms ${ }^{1}$, Annelies Maenhout ${ }^{1}$

ABSTRACT | The shoulder is at high risk for injury during overhead sports, in particular in throwing or hitting activities, such as baseball, tennis, handball, and volleyball. In order to create a scientific basis for the prevention of recurrent injuries in overhead athletes, four steps need to be undertaken: (1) risk factors for injury and re-injury need to be defined; (2) established risk factors may be used as return-to-play criteria, with cut-off values based on normative databases; (3) these variables need to be measured using reliable, valid assessment tools and procedures; and (4) preventative training programs need to be designed and implemented into the training program of the athlete in order to prevent re-injury. In general, three risk factors have been defined that may form the basis for recommendations for the prevention of recurrent injury and return to play after injury: glenohumeral internal-rotation deficit (GIRD); rotator cuff strength, in particular the strength of the external rotators; and scapular dyskinesis, in particular scapular position and strength.

Keywords: shoulder; injury prevention; return to play.

\section{HOW TO CITE THIS ARTICLE}

Cools AM, Johansson FR, Borms D, Maenhout A. Prevention of shoulder injuries in overhead athletes: a science-based approach. Braz J Phys Ther. 2015 Sept-Oct; 19(5):331-339. http://dx.doi.org/10.1590/bjpt-rbf.2014.0109

\section{Introduction}

The shoulder is at high risk of injury in overhead sports like tennis or volleyball because it faces high loads and forces during serving and smashing. Injury risk seems to increase with age ${ }^{1,2}$ and, despite some lack of evidence, has been suggested to be related to level and volume of play ${ }^{2-4}$.

Most of the reported shoulder injuries are strains, implicating a process over time, with chronic overload leading to injury ${ }^{1}$. Chronic shoulder pain in the overhead athlete is often attributed to sport-specific adaptations, alterations in strength, flexibility, and posture not only in the glenohumeral joint, but also in other links of the kinetic chain ${ }^{5-9}$. These alterations change biomechanics and movement strategies during serving and striking, possibly leading to overload injuries at the shoulder. In particular, glenohumeral internal-rotation deficit (GIRD), rotator cuff strength imbalance, scapular dyskinesis, thoracic spine stiffness and hyperkyphosis, lumbar core instability, and hip range of motion and strength deficits possibly create the "cascade to injury", as defined by Kibler ${ }^{10}$ and Lintner et al. ${ }^{7}$ in overhead athletes. This kinetic chain "breakage" has been suggested to be a result of repetitive, vigorous activities in both young and older athletes ${ }^{7,10,11}$. In spite of the relevance of kinetic chain alterations in the spine and lower extremities, the discussion of these variables is beyond the scope of this paper, which focusses on more local shoulder girdle factors.

In order to create a scientific basis for the prevention of recurrent injuries in overhead athletes, four steps need to be undertaken: (1) risk factors for injury and re-injury need to be defined ${ }^{12}$; (2) established risk factors may be used as return-to-play criteria, with cut-off values based on normative databases; (3) these variables need to be measured using reliable, valid assessment tools and procedures; and (4) preventive training programs need to be designed and implemented into the training program of the athlete in order to prevent re-injury. The purpose of the present paper is to review the literature regarding these steps and to suggest some clinical applications of the current knowledge to the clinician.

\section{Risk factors for shoulder injury in overhead athletes}

In spite of promising results from prospective studies, no consensus exists regarding intrinsic risk factors for shoulder pain in the overhead athlete. 
Different requirements on the shoulder and specific throwing activities across the spectrum of overhead athletes might account for these discrepancies. Recently GIRD and rotator cuff strength deficit, as well as scapular dyskinesis have been defined as possible risk factors in a population of baseball, rugby, and handball players ${ }^{13-18}$. In particular, pre-season reduced internal rotation range of motion ${ }^{14}$, reduced total range of motion ${ }^{13,15}$, a strength deficit in the external rotators ${ }^{13,16,17}$, and inadequate scapular position during clinical testing ${ }^{13,18}$ were shown to increase the risk for overuse chronic shoulder pain in these athletes.

Posterior shoulder stiffness is a common, if not the most common, adaptation seen on the dominant side of overhead athletes of multiple sports disciplines ${ }^{8}$. This manifests clinically as decreased glenohumeral cross-body adduction and internal rotation mobility and is believed to be the result of both capsular tightness and muscular contracture. It is hypothesized that the cumulative loads onto the posterior shoulder during the deceleration phase of the throwing motion cause microtrauma and scarring of these soft tissues ${ }^{8}$. Posterior shoulder stiffness, therefore, has been suggested to be a causative or perpetuating factor in shoulder impingement and labral pathology $y^{9,19,20}$. Abnormal humeral head translations, caused by selective tightening of the posterior-inferior capsule, may decrease the width of the subacromial space, thus causing subacromial impingement ${ }^{21}$. Other studies ${ }^{22}$ suggest a posterior and superior translation of the humeral head during cocking with a tight posterior capsule, possibly leading to an encroachment of the rotator cuff tendons against the postero-superior rim of the glenoid. In addition, posterior shoulder tightness seems to affect kinematics of the scapula and the humeral head. and is associated with a decreased acromiohumeral distance ${ }^{23}$. As a result, posterior capsule shortness possibly increases the risk for internal as well as subacromial impingement in the overhead athlete ${ }^{21,22}$. Recently, Clarsen et al. ${ }^{13}$ showed an odds ratio for sports-related shoulder pain of 0.77 per $5^{\circ}$ change in total range of motion (adding up internal and external range of motion) in a population of handball players.

During overhead throwing and serving, the shoulder is highly loaded with an enormous challenge for the eccentric capacity of the external rotators during the deceleration phase. In specific sports such as tennis, it has been shown that elite players without shoulder injury have shoulder rotation muscle strength imbalances that alter the ratio between rotator cuff muscles ${ }^{24}$. Although these differences do not seem to affect the athletic performance immediately, detection and prevention with exercise programs at an early age are recommended, since recently decreased external rotation strength has been identified as a risk factor for shoulder pain ${ }^{13}$.

There is a body of evidence showing an association between scapular dysfunction and shoulder pain, specifically in the overhead athlete ${ }^{25-30}$, however there is no consensus regarding the cause-consequence relationship between both clinical entities. Some studies revealed no causative relationship between scapular dysfunction and shoulder pain ${ }^{31,32}$, whereas others clearly identified scapular dyskinesis as a possible risk factor for chronic shoulder pain in a population of overhead athletes ${ }^{13,18,31}$. In particular, obvious scapular dyskinesis, as defined by McClure et al..$^{33}$, and type III scapular dyskinesis, as defined by Kibler et al. ${ }^{34}$, were found to increase the risk for shoulder pain ${ }^{13,18}$. Other studies discussed scapular position in healthy tennis players, but also with conflicting results. While Silva et al. ${ }^{35}$ showed abnormal scapular position correlated with decreased acromiohumeral distance, Cools et al ${ }^{36}$ described positive alterations in elite tennis players with increased scapular upward rotation on the dominant side.

In summary, glenohumeral range of motion, rotator cuff strength or imbalance, and scapular position and movement are important factors in the assessment of healthy and previously injured overhead athletes in order to define risk factors and guide the athlete into the return-to-play stage after injury.

In addition to the more local risk factors mentioned above, more functional deficits might be risk factors for injury like faulty biomechanics, throwing fatigue etc. In order to measure these variables, there is a need for functional testing in a throwing-specific position, for instance endurance tests of the shoulder into a throwing position, throwing distance, speed and accuracy. However, with the exception of some tests mimicking shoulder function, like the "seated medicine ball throw" ${ }^{37}$ or the "Y-balance test for the upper limb" 38 , to date no science-based functional test has been fully validated to determine risk factors for shoulder injury or return to play after injury.

\section{Return-to-play criteria based on cut-off values from the risk factors}

According to the decision-based return-to-play model described by Matheson et al. ${ }^{39}, 3$ steps need to be taken prior to full return to sports. First, the health status of the athlete is evaluated, including 
assessment of symptoms and a battery of analytical and functional tests (e.g. strength and flexibility, throwing performance, etc.). Then, the clinician evaluates the participation risk based on the type of sport, level of competition, and ability to protect the shoulder. Finally, some factors might modify the decision, such as the timing in the season, pressure from the athlete, or his environment. However, in spite of this science-based model to be implemented into clinical practice, little evidence exists regarding the physical return-to-play criteria of the shoulder after injury. From a clinical perspective, there is a need for cut-off values for each of the described risk factors to be used as criteria for return to training and return to play. In addition, the clinician needs objective and valid assessment tools applicable to the athlete's field or training area. Finally, once deficits are assessed, there is a need for science-based training programs to restore normal values. The purpose of the following paragraphs is to discuss cut-off values, assessment tools, and intervention programs for GIRD, rotator cuff strength deficit, and scapular dyskinesis.

\section{Glenohumeral range of motion}

With respect to range of motion, loss of internal range of motion is a known risk factor for chronic shoulder pain ${ }^{14,15,40}$. There is no consensus in literature with respect to the cut-off values for internal ROM, ranging from $18^{\circ 15}$ up to $25^{\circ 14}$ depending on the study design and population. Therefore, in view of maximal protection of the athlete, it is advised that side differences in internal rotation ROM should be less than $18^{\circ}$, and the difference in total range of motion should be no more than $5^{\circ 15}$. The studies referring to selectively measuring GIRD, base their instruction on the proposition that it is the result of selective tightening of the posterior shoulder structures, such as the posterior capsule of the glenohumeral joint and the posterior cuff muscles. The relevance of the concept of total range of motion, in which internal and external ROM are added up, has been introduced in the literature since the first studies showing bony adaptations in the humeral torsion based on overhead sports activity ${ }^{41}$. Increased humeral torsion alters the arc of total range of motion into decreased internal rotation ROM and increased external rotation ROM. In this hypothesis, the athlete is not at risk as long as the loss of IR is compensated by a gain of ER. Therefore, it is advised, in particular in elite athletes, to take into account the total ROM rather than the internal rotation ROM as a risk factor. A recent study on professional baseball players found that pitchers with GIRD displayed greater side-to-side differences and dominant humeral retrotorsion compared to those without GIRD. The authors concluded that the greater humeral retrotorsion may place greater stress on the posterior shoulder resulting in ROM deficits. Pitchers with greater humeral retrotorsion appear to be more susceptible to developing ROM deficits associated with injury and may need increased monitoring and customized treatment programs to mitigate their increased injury risk ${ }^{42}$.

The assessment of the ROM into rotation of the shoulder can be measured with a goniometer or an inclinometer, and in many positions of the body and the shoulder. A comprehensive reliability study ${ }^{43}$ showed high to excellent inter- and intra-tester reliability for a variety of test positions and equipment. Based on the results of this study, no specific procedure can be acknowledged to be superior to another one. However, the clinician has to take into account that there is great variability in the literature regarding shoulder position (e.g. scapular or frontal plane) $)^{15,24}$ and the specific method of scapular stabilization (none, hand on shoulder top, or specific fixation of coracoid). Based on the above-mentioned reliability study and in view of optimal standardization of body and shoulder position, the authors advise the following procedure: the patient is supine with the shoulder in the frontal plane and the elbow flexed $90^{\circ}$. The upper arm should be horizontal or if needed the arm can be supported by a towel to reach the horizontal position (for instance in case the patient has protracted shoulders or a thoracic kyphosis). For internal rotation, the examiner palpates the spine of the scapula and the coracoid. The inclinometer is aligned with the forearm (olecranon and styloid process of the ulna), and the shoulder is moved into internal rotation (Figure 1). The movement reaches

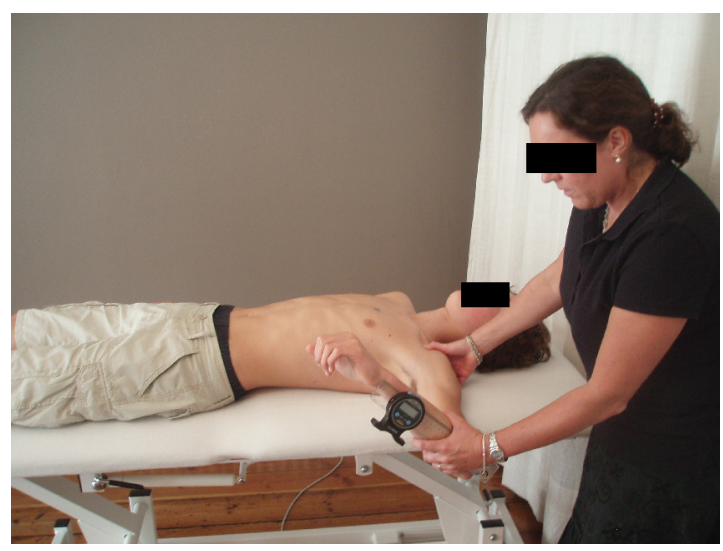

Figure 1. Measurement of internal rotation of the shoulder using a digital inclinometer ${ }^{24}$. 
its endpoint when the coracoid tends to move against the palpating thumb. For external rotation, the fixating hand is placed gently over the shoulder top, and the shoulder is moved into external rotation, aligning the inclinometer with the forearm.

In addition, horizontal adduction can be measured in the assessment of posterior capsule stiffness ${ }^{23}$. It is advised that measurement be performed with the shoulder at $90^{\circ}$ of flexion and horizontally adducted until the scapula starts moving laterally. While one investigator manually fixes the lateral border of the scapula and palpates the lateral movement of the scapula, the second moves the upper arm toward horizontal adduction and measures the angle between the upper arm and the vertical ${ }^{23}$. In spite of the clinical relevance of this measurement, its predictive value in shoulder pain is unclear.

Given the evidenced impact of posterior shoulder tightness on shoulder kinematics, increasing posterior shoulder flexibility is advised when mobility deficits exceed the limits associated with increased injury risk. Both the cross-body stretch (Figure 2) and the sleeper stretch (Figure 3) can be recommended to decrease posterior shoulder tightness ${ }^{44}$. It was shown that a 6 -week daily sleeper stretch program (3 reps of 30 seconds)

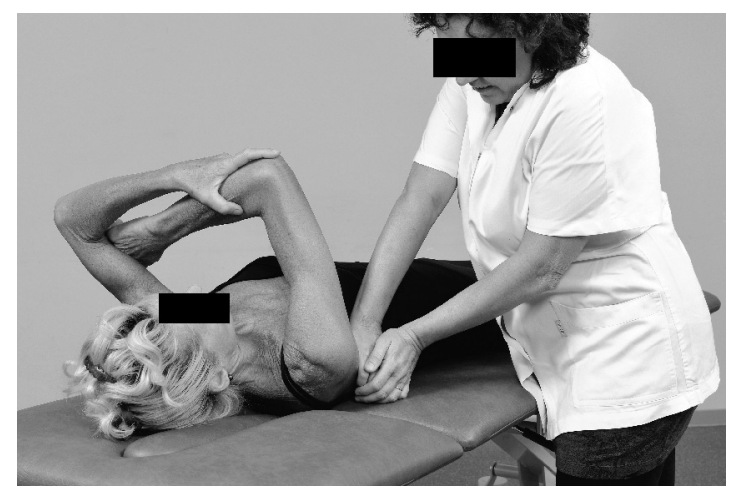

Figure 2. Cross body stretch' .

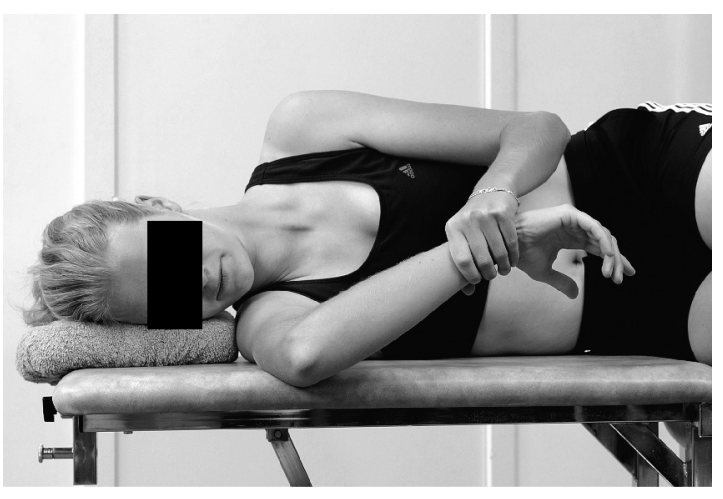

Figure 3. Sleeper's stretch ${ }^{41}$. is able to significantly increase the acromiohumeral distance in the dominant shoulder of healthy overhead athletes with GIRD ${ }^{23}$. Additional joint mobilization performed by a physical therapist has a small but non-significant advantage over a home stretching program alone ${ }^{45}$. No difference in mobility gain was seen after angular (sleeper stretch and horizontal adduction stretch) and non-angular (dorsal and caudal humeral head glides) joint mobilization by a physical therapist ${ }^{46}$ in a 3-week stretching program in overhead athletes with impingement-related shoulder pain. Both programs however resulted in increased ROM and decreased pain during physical examination and improved shoulder functional outcome scores. Muscle energy techniques (hold-relax) during the sleeper stretch and the horizontal adduction stretch have proven useful to immediately increase internal rotation range of motion ${ }^{47}$. Two studies ${ }^{46,48}$ showed symptom relief after a stretching program in a population of overhead athletes with impingement-related shoulder pain. However, there is no evidence to support that a stretching program reduces the incidence of recurrent shoulder injury.

\section{Rotator cuff strength}

Regarding rotator cuff strength, it is generally recognized that overhead athletes often exhibit sport-specific adaptations leading to a relative decrease in the strength of the external rotators, and thus muscular imbalance in the rotator cuff. Isokinetic ${ }^{49}$ as well as isometric ${ }^{24}$ and eccentric ${ }^{50}$ strength studies have been performed in healthy and injured athletes showing deficiencies in external rotator muscle performance. In these studies, absolute side differences as well as muscle balance ratio between external and internal rotators were examined. In general, with respect to cut-off values distinguishing a healthy shoulder from a shoulder at risk, an isokinetic ER/IR ratio of $66 \%$ or an isometric ER/IR ratio of $75 \%$ is advised, with a general rotator cuff strength increase of $10 \%$ of the dominant throwing side s6,24,49 $^{1}$ compared to the non-dominant side. Recently, focus has shifted from isometric or concentric to eccentric muscle strength of the rotator cuff. In particular, the eccentric strength of the external rotators are of interest ${ }^{51}$. These muscles function as a decelerator mechanism during powerful throwing, serving, or smashing.

In view of the importance of eccentric rotator cuff strength in relation to injury-free overhead throwing or serving, it is imperative that strength be assessed on a regular base in healthy as well as injured players. 
Numerous testing protocols have been described to examine isokinetic ${ }^{52-54}$ and isometric ${ }^{55}$ rotator cuff strength. The golden standard in strength measurement is the use of isokinetic devices, however these procedures are rather expensive, and not applicable on the field or training area. With respect to the isometric strength measurements, hand-held dynamometry (HHD) has attracted more and more interest during the last years due to the more practical, less expensive and user-friendly advantages over the more advanced and expensive isokinetic devices. HHD has demonstrated higher sensitivity and intra- and inter-examiner reliability than manual muscle testing in identifying strength deficits of the rotator cuff ${ }^{56}$.

Recently, a new testing protocol was published, showing that HHD measurements of eccentric external rotator strength show excellent intra-tester $(\mathrm{ICC}=0.88$ ) and good inter-tester $(\mathrm{ICC}=0.71)$ reliability, as well as concurrent validity (compared to an isokinetic device, Pearson's correlation $=0.78)^{51}$. During the procedure, the patient is seated gently supported by the arm of the tester, who brings the shoulder from $90^{\circ}$ abduction $-90^{\circ}$ external rotation (throwing position) to $90^{\circ}$ abduction $-0^{\circ}$ external rotation, loading the external rotators eccentrically (Figure 4). A large normative database on 200 overhead athletes (volleyball, tennis, and handball) was recently set up (unpublished data) and shows an average normalized eccentric external rotator strength $(\mathrm{N} / \mathrm{kg})$ of approximately 2 , with significant side differences in favor of the dominant sides, and significant higher values for handball and tennis compared to volleyball.

Numerous exercises have been described to strengthen the rotator cuff muscles, including concentric, isometric, eccentric, and plyometric exercises ${ }^{41}$. In view of the eccentric component of the function of the external rotators, the sport-specific exercises for overhead athletes should focus on three areas:

1) Exercises that accentuate the eccentric phase and "avoid" the concentric phase in order to load the muscles based on their eccentric capacity. Figures 5 A-C show an example of an eccentric exercise for the external rotators in general in an abducted position.

2) Slow exercises for absolute strength, fast exercises for endurance and plyometric capacity. Endurance and plyometric capacity may be exercised using weight balls exercises in which the patient is instructed to "catch" the ball (Figure 6), as described by Ellenbecker and Cools ${ }^{41}$.

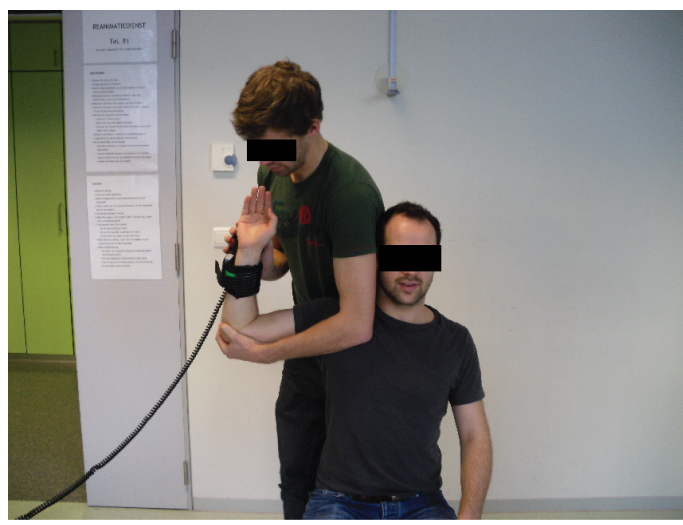

Figure 4. Eccentric testing protocol using an $\mathrm{HHD}^{51}$.
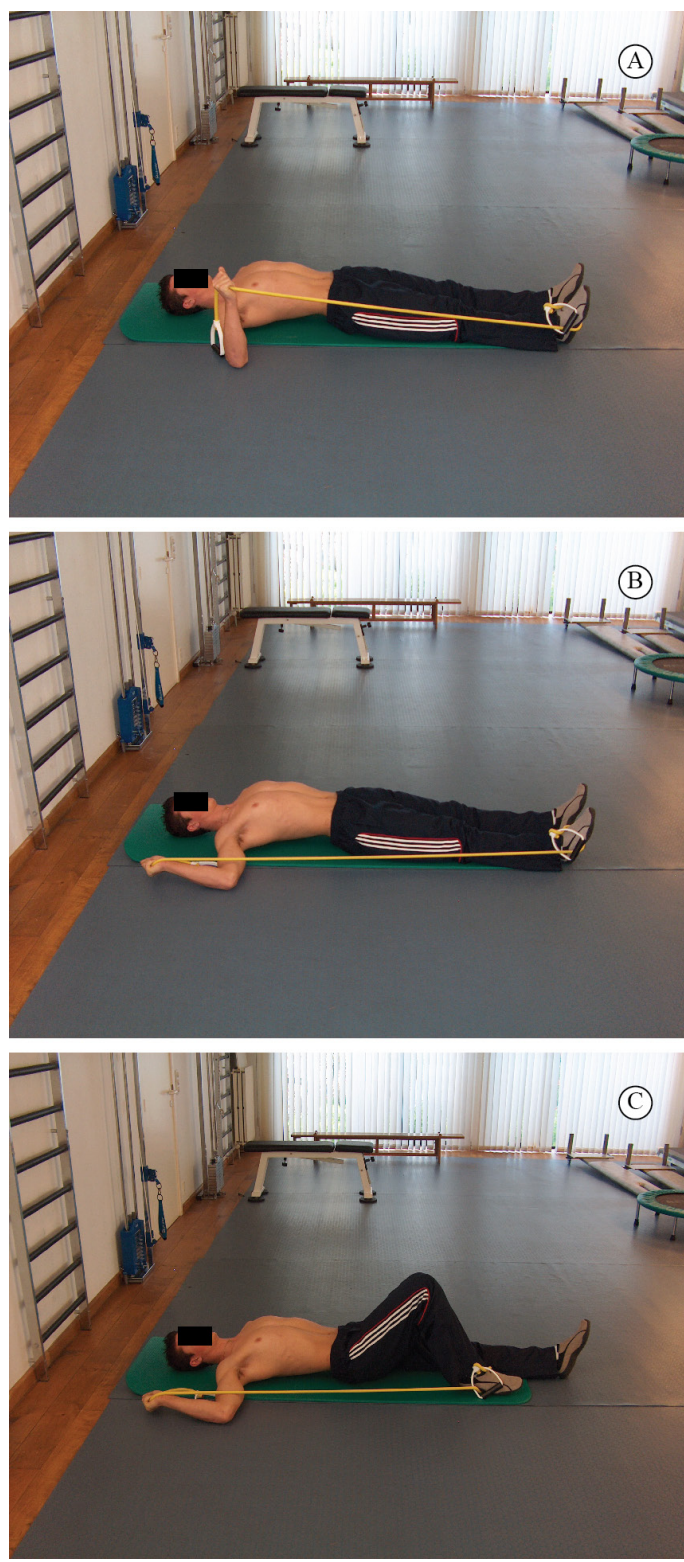

Figure 5. Eccentric exercise for the external rotators in an abducted position. 
3) Exercise highlighting the "stretch-shortening-cycle" of throwing. Specific devices can be used to train the stretch-shortening cycle, such as $\mathrm{XCO}^{\circledR}$ trainer (Figure 7).

\section{Scapular dyskinesis}

Evidence supporting cut-off values for prevention of injury or return to play after injury with respect to scapular function is scarce. A number of studies used visual observation as a criterion ${ }^{13,18}$ whereas others provide objective data on healthy athletes as a reference base for return to play ${ }^{36,57}$. In general, visual observation is performed either by using the yes/no method (scapular dyskinesis or not), a method proven to be reliable and valid if the examiner/therapist is educated in a standardized manner ${ }^{33,58}$, or by categorizing the scapular dysfunction into different types, based on the specific position of the scapula ${ }^{34}$. However, the latter method was shown to have acceptable intra-rater, but low inter-rater reliability ${ }^{34}$. Clarsen et al. ${ }^{13}$ rated scapular dyskinesis in handball players as having normal scapular control, slight scapular dyskinesis, or obvious

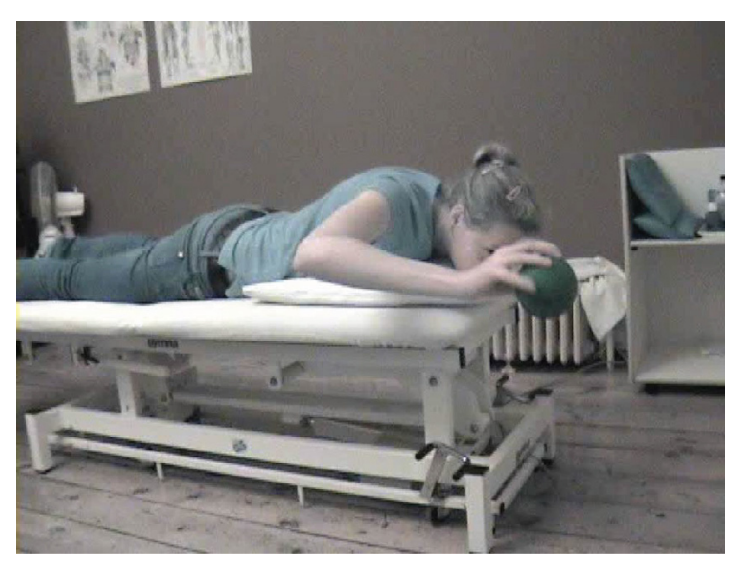

Figure 6. "Catching" exercise using a plyoball ${ }^{41}$.

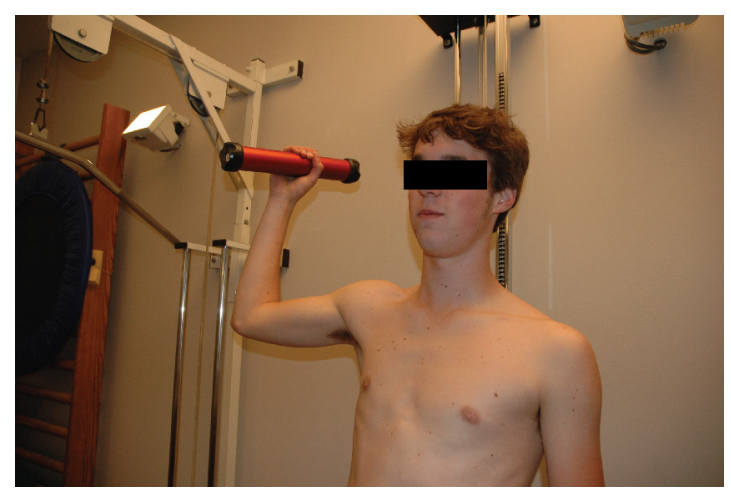

Figure 7. Stretch-shortening cycle exercise, using the $\mathrm{XCO}^{\circledR}$ trainer. dyskinesis $^{13}$, and established obvious dyskinesis as a risk factor for shoulder pain. A statement saying that scapular behavior should be symmetrical in overhead athletes is not supported by research data. On the contrary, in volleyball as well as in handball players, asymmetry was found in resting scapular posture ${ }^{57,59}$. Uhl et al..$^{58}$ also reported that the prevalence of scapular dyskinesis was almost identical in subjects with and without shoulder pain, questioning the clinical value of scapular asymmetry. Therefore, clinicians should be aware that some degree of scapular asymmetry may be normal in some athletes. It should not be considered automatically as a pathological sign, but rather an adaptation to sports practice and extensive use of upper limb.

Several studies measured scapular upward inclination in healthy overhead athletes ${ }^{46,60}$. These data may be used as a reference base and cut-off values for correct scapular positioning in several elevation angles. In general, a large variety is found in scapular upward inclination in the midrange of motion (probably due to a large variation between individuals), however in full elevation, most studies suggest that upward inclination should be at least $45-55^{\circ 36,60}$.

For the scapular muscles proper inter- and intramuscular balance should be assessed. Isokinetic ratio protraction/retraction is shown to be $100 \%$ in a healthy population, with slight changes in overhead athletes, in case of throwing athletes in favor of the protractors ${ }^{25,36,61}$. In bilateral sports (swimming, rowing, gymnastics), there should be no side differences in scapular muscle strength. In one-handed overhead sports, an increase of $10 \%$ in scapular muscle strength is advised on the dominant side. In particular, the lower trapezius and serratus anterior should receive special attention, since these muscles are shown to be susceptible to weakness in injured athletes ${ }^{10,62}$.

In the assessment of scapular behavior, besides the clinical observation, several measurements can be performed for scapular position as well as muscle strength. The use of a digital inclinometer for the measurement of scapular upward rotation has been shown to exhibit high inter- and intra-rater reliability ${ }^{60}$. Key conditions for good measurements are adequate palpation of the reference points in the different humeral elevation angles and control of additional tilting of the inclinometer in planes other than the scapular plane. For the measurement of scapular muscle strength, several protocols have been described ${ }^{36,63}$. Differences between procedures are based on the equipment used, positioning of the 
dynamometer, patient positioning, and performing a "make" and "break" test. Different testing procedures result in different outcome, the clinician should take that into account using reference data from research in the clinical practice. In the authors' experience, using the Kendall \& Kendall position and performing a "make" test with a hand held dynamometer is an acceptable and clinically relevant method of strength measurement of the scapular muscles ${ }^{36}$.

Once deficits and imbalances in scapular behavior are assessed, an intervention program to restore flexibility and muscle performance needs to be installed. Recently, a science-based clinical reasoning algorithm was published guiding the clinician into the different steps and progression ${ }^{62}$. The main goals are: a) to restore flexibility of the surrounding soft tissue of the scapula, in particular pectoralis minor, levator scapulae, rhomboid, and posterior shoulder structures; and b) to increase scapular muscle performance around the scapula, focusing on either muscle control and inter- and intramuscular coordination or muscle strength and balance. Exercises to restore scapular muscle balance ${ }^{64}$ have been shown to increase isokinetic protraction and retraction ${ }^{65}$, increase external rotator strength of the shoulder ${ }^{66}$, and alter EMG activity of the scapular muscles in favor of efficient muscle recruitment during a loaded elevation task ${ }^{67}$.

\section{Conclusion}

In summary, with respect to injury prevention as well as return to play after injury, the clinician should evaluate possible risk factors for injury in the shoulder, in particular GIRD, rotator cuff strength, and scapular performance, using reliable assessment tools. In case abnormal findings are established, the intervention should focus on stretching of the posterior shoulder capsule, strengthening of the posterior cuff, and restoration of flexibility and muscle balance of the scapular muscles.

\section{References}

1. Kibler WB, Safran MR. Musculoskeletal injuries in the young tennis player. Clin Sports Med. 2000;19(4):781-92. http:// dx.doi.org/10.1016/S0278-5919(05)70237-4. PMid:11019740.

2. Pluim BM, Staal JB, Windler GE, Jayanthi N. Tennis injuries: occurrence, aetiology, and prevention. Br J Sports Med. 2006;40(5):415-23. http://dx.doi.org/10.1136/bjsm.2005.023184. PMid:16632572.

3. Baxter-Jones A, Maffulli N, Helms P. Low injury rates in elite athletes. Arch Dis Child. 1993;68(1):130-2. http:// dx.doi.org/10.1136/adc.68.1.130. PMid:8434997.
4. Jayanthi NA, O'Boyle J, Durazo-Arvizu RA. Risk factors for medical withdrawals in United States tennis association junior national tennis tournaments: a descriptive epidemiologic study. Sports Health. 2009;1(3):231-5. http://dx.doi. org/10.1177/1941738109334274. PMid:23015877.

5. Sciascia A, Kibler WB. The pediatric overhead athlete: what is the real problem? Clin J Sport Med. 2006;16(6):471-7. http://dx.doi.org/10.1097/01.jsm.0000251182.44206.3b. PMid:17119360.

6. Kibler WB, Press J, Sciascia A. The role of core stability in athletic function. Sports Med. 2006;36(3):189-98. http://dx.doi. org/10.2165/00007256-200636030-00001. PMid:16526831.

7. Lintner D, Noonan TJ, Kibler WB. Injury patterns and biomechanics of the athlete's shoulder. Clin Sports Med. 2008;27(4):527-51. http://dx.doi.org/10.1016/j.csm.2008.07.007. PMid:19064144.

8. Borsa PA, Laudner KG, Sauers EL. Mobility and stability adaptations in the shoulder of the overhead athlete: a theoretical and evidence-based perspective. Sports Med. 2008;38(1):17-36. http://dx.doi.org/10.2165/00007256200838010-00003. PMid:18081365.

9. Cools AM, Declercq G, Cagnie B, Cambier D, Witvrouw E. Internal impingement in the tennis player: rehabilitation guidelines. Br J Sports Med. 2008;42(3):165-71. http:// dx.doi.org/10.1136/bjsm.2007.036830. PMid:18070811.

10. Kibler WB. The role of the scapula in athletic shoulder function. Am J Sports Med. 1998;26(2):325-37. PMid:9548131.

11. Kibler WB, McMullen J. Scapular dyskinesis and its relation to shoulder pain. J Am Acad Orthop Surg. 2003;11(2):14251. PMid: 12670140.

12. Bahr R, Krosshaug T. Understanding injury mechanisms: a key component of preventing injuries in sport. Br J Sports Med. 2005;39(6):324-9. http://dx.doi.org/10.1136/ bjsm.2005.018341. PMid:15911600.

13. Clarsen B, Bahr R, Andersson SH, Munk R, Myklebust G. Reduced glenohumeral rotation, external rotation weakness and scapular dyskinesis are risk factors for shoulder injuries among elite male handball players: a prospective cohort study. Br J Sports Med. 2014;48(17):1327-33. http://dx.doi. org/10.1136/bjsports-2014-093702. PMid:24948083.

14. Shanley E, Rauh MJ, Michener LA, Ellenbecker TS, Garrison JC, Thigpen CA. Shoulder range of motion measures as risk factors for shoulder and elbow injuries in high school softball and baseball players. Am J Sports Med. 2011;39(9):1997-2006. http://dx.doi.org/10.1177/0363546511408876. PMid:21685316.

15. Wilk KE, Macrina LC, Fleisig GS, Porterfield R, Simpson CD 2nd, Harker P, et al. Correlation of glenohumeral internal rotation deficit and total rotational motion to shoulder injuries in professional baseball pitchers. Am J Sports Med. 2011;39(2):329-35. http://dx.doi.org/10.1177/0363546510384223. PMid:21131681.

16. Byram IR, Bushnell BD, Dugger K, Charron K, Harrell FE Jr, Noonan TJ. Preseason shoulder strength measurements in professional baseball pitchers: identifying players at risk for injury. Am J Sports Med. 2010;38(7):1375-82. http:// dx.doi.org/10.1177/0363546509360404. PMid:20489215.

17. Edouard P, Degache F, Oullion R, Plessis JY, Gleizes-Cervera $\mathrm{S}$, Calmels P. Shoulder strength imbalances as injury risk in handball. Int J Sports Med. 2013;34(7):654-60. http:// dx.doi.org/10.1055/s-0032-1312587. PMid:23444085.

18. Kawasaki T, Yamakawa J, Kaketa T, Kobayashi H, Kaneko K. Does scapular dyskinesis affect top rugby players during a game season? J Shoulder Elbow Surg. 2012;21(6):709-14. http://dx.doi.org/10.1016/j.jse.2011.11.032. PMid:22445626. 
19. Burkhart SS, Morgan CD, Kibler WB. The disabled throwing shoulder: spectrum of pathology Part I: pathoanatomy and biomechanics. Arthroscopy. 2003;19(4):404-20. http://dx.doi. org/10.1053/jars.2003.50128. PMid:12671624.

20. Wilk KE, Obma P, Simpson CD 2nd, Cain EL, Dugas JR, Andrews JR. Shoulder injuries in the overhead athlete. J Orthop Sports Phys Ther. 2009;39(2):38-54. http://dx.doi. org/10.2519/jospt.2009.2929. PMid:19194026.

21. Huffman GR, Tibone JE, McGarry MH, Phipps BM, Lee YS, Lee TQ. Path of glenohumeral articulation throughout the rotational range of motion in a thrower's shoulder model. Am J Sports Med. 2006;34(10):1662-9. http://dx.doi. org/10.1177/0363546506287740. PMid:16685095.

22. Gagey OJ, Boisrenoult P. Shoulder capsule shrinkage and consequences on shoulder movements. Clin Orthop Relat Res. 2004;419:218-22. http://dx.doi.org/10.1097/00003086200402000-00036. PMid:15021158.

23. Maenhout A, Van Eessel V, Van Dyck L, Vanraes A, Cools A. Quantifying acromiohumeral distance in overhead athletes with glenohumeral internal rotation loss and the influence of a stretching program. Am J Sports Med. 2012;40(9):2105-12. http://dx.doi.org/10.1177/0363546512454530. PMid:22869627.

24. Cools AM, Palmans T, Johansson FR. Age-related, sportspecific adaptions of the shoulder girdle in elite adolescent tennis players. J Athl Train. 2014;49(5):647-53. http://dx.doi. org/10.4085/1062-6050-49.3.02. PMid:25098662.

25. Cools AM, Declercq GA, Cambier DC, Mahieu NN, Witvrouw EE. Trapezius activity and intramuscular balance during isokinetic exercise in overhead athletes with impingement symptoms. Scand J Med Sci Sports. 2007;17(1):25-33. PMid: 16774650

26. Cools AM, Witvrouw EE, Declercq GA, Danneels LA, Cambier DC. Scapular muscle recruitment patterns: trapezius muscle latency with and without impingement symptoms. Am J Sports Med. 2003;31(4):542-9. PMid:12860542.

27. Ludewig PM, Reynolds JF. The association of scapular kinematics and glenohumeral joint pathologies. J Orthop Sports Phys Ther. 2009;39(2):90-104. http://dx.doi.org/10.2519/ jospt.2009.2808. PMid:19194022.

28. Struyf F, Cagnie B, Cools A, Baert I, Brempt JV, Struyf $\mathrm{P}$, et al. Scapulothoracic muscle activity and recruitment timing in patients with shoulder impingement symptoms and glenohumeral instability. J Electromyogr Kinesiol. 2014;24(2):277-84. http://dx.doi.org/10.1016/j.jelekin.2013.12.002. PMid:24389333.

29. Lopes AD, Timmons MK, Grover M, Ciconelli RM, Michener LA. Visual scapular dyskinesis: kinematics and muscle activity alterations in patients with subacromial impingement syndrome. Arch Phys Med Rehabil. 2015;96(2):298-306. http://dx.doi.org/10.1016/j.apmr.2014.09.029. PMid:25449194.

30. Huang TS, Ou HL, Huang CY, Lin JJ. Specific kinematics and associated muscle activation in individuals with scapular dyskinesis. J Shoulder Elbow Surg. 2015 [Epub ahead of print]. http://dx.doi.org/10.1016/j.jse.2014.12.022.

31. Struyf F, Nijs J, Meeus M, Roussel NA, Mottram S, Truijen $\mathrm{S}$, et al. Does scapular positioning predict shoulder pain in recreational overhead athletes? Int J Sports Med. 2014;35(1):75-82. PMid:23825003.

32. Myers JB, Oyama S, Hibberd EE. Scapular dysfunction in high school baseball players sustaining throwing-related upper extremity injury: a prospective study. J Shoulder Elbow Surg. 2013;22(9):1154-9. http://dx.doi.org/10.1016/j. jse.2012.12.029. PMid:23419606.

33. McClure P, Tate AR, Kareha S, Irwin D, Zlupko E. A clinical method for identifying scapular dyskinesis, part
1: reliability. J Athl Train. 2009;44(2):160-4. http://dx.doi. org/10.4085/1062-6050-44.2.160. PMid:19295960.

34. Kibler WB, Uhl TL, Maddux JW, Brooks PV, Zeller B, McMullen J. Qualitative clinical evaluation of scapular dysfunction: a reliability study. J Shoulder Elbow Surg. 2002;11(6):550-6. http://dx.doi.org/10.1067/mse.2002.126766. PMid:12469078.

35. Silva RT, Hartmann LG, Laurino CF, Biló JP. Clinical and ultrasonographic correlation between scapular dyskinesia and subacromial space measurement among junior elite tennis players. Br J Sports Med. 2010;44(6):407-10. http:// dx.doi.org/10.1136/bjsm.2008.046284. PMid:18397969.

36. Cools AM, Johansson FR, Cambier DC, Velde AV, Palmans T, Witvrouw EE. Descriptive profile of scapulothoracic position, strength and flexibility variables in adolescent elite tennis players. Br J Sports Med. 2010;44(9):678-84. http://dx.doi.org/10.1136/bjsm.2009.070128. PMid:20587640.

37. van den Tillaar R, Marques MC. Reliability of seated and standing throwing velocity using differently weighted medicine balls. J Strength Cond Res. 2013;27(5):1234-8. http:/ dx.doi.org/10.1519/JSC.0b013e3182654a09. PMid:22744301.

38. Westrick RB, Miller JM, Carow SD, Gerber JP. Exploration of the y-balance test for assessment of upper quarter closed kinetic chain performance. Int J Sports Phys Ther. 2012;7(2):139-47. PMid:22530188.

39. Matheson GO, Shultz R, Bido J, Mitten MJ, Meeuwisse WH, Shrier I. Return-to-play decisions: are they the team physician's responsibility? Clin J Sport Med. 2011;21(1):2530. http://dx.doi.org/10.1097/JSM.0b013e3182095f92. PMid:21200167.

40. Shanley E, Thigpen CA, Clark JC, Wyland DJ, Hawkins RJ, Noonan TJ, et al. Changes in passive range of motion and development of glenohumeral internal rotation deficit (GIRD) in the professional pitching shoulder between spring training in two consecutive years. J Shoulder Elbow Surg. 2012;21(11):1605-12. http://dx.doi.org/10.1016/j. jse.2011.11.035. PMid:22835630.

41. Ellenbecker TS, Cools A. Rehabilitation of shoulder impingement syndrome and rotator cuff injuries: an evidencebased review. Br J Sports Med. 2010;44(5):319-27. http:// dx.doi.org/10.1136/bjsm.2009.058875. PMid:20371557.

42. Noonan TJ, Shanley E, Bailey LB, Wyland DJ, Kissenberth MJ, Hawkins RJ, et al. Professional Pitchers With Glenohumeral Internal Rotation Deficit (GIRD) Display Greater Humeral Retrotorsion Than Pitchers Without GIRD. Am J Sports Med. 2015;43(6):1448-54. http://dx.doi. org/10.1177/0363546515575020. PMid:25807953.

43. Cools AM, De Wilde L, Van Tongel A, Ceyssens C, Ryckewaert $\mathrm{R}$, Cambier DC. Measuring shoulder external and internal rotation strength and range of motion: comprehensive intra-rater and inter-rater reliability study of several testing protocols. J Shoulder Elbow Surg. 2014;23(10):1454-61. http://dx.doi.org/10.1016/j.jse.2014.01.006. PMid:24726484.

44. McClure P, Balaicuis J, Heiland D, Broersma ME, Thorndike CK, Wood A. A randomized controlled comparison of stretching procedures for posterior shoulder tightness. J Orthop Sports Phys Ther. 2007;37(3):108-14. http://dx.doi. org/10.2519/jospt.2007.2337. PMid:17416125.

45. Manske RC, Meschke M, Porter A, Smith B, Reiman M. A randomized controlled single-blinded comparison of stretching versus stretching and joint mobilization for posterior shoulder tightness measured by internal rotation motion loss. Sports Health. 2010;2(2):94-100. http://dx.doi. org/10.1177/1941738109347775. PMid:23015927. 
46. Cools AM, Johansson FR, Cagnie B, Cambier DC, Witvrouw EE. Stretching the posterior shoulder structures in subjects with internal rotation deficit: comparison of two stretching techniques. Shoulder Elbow. 2012;4(1):56-63. http://dx.doi. org/10.1111/j.1758-5740.2011.00159.x.

47. Moore SD, Laudner KG, McLoda TA, Shaffer MA. The immediate effects of muscle energy technique on posterior shoulder tightness: a randomized controlled trial. J Orthop Sports Phys Ther. 2011;41(6):400-7. http://dx.doi.org/10.2519/ jospt.2011.3292. PMid:21471651.

48. Tyler TF, Nicholas SJ, Lee SJ, Mullaney M, McHugh MP. Correction of posterior shoulder tightness is associated with symptom resolution in patients with internal impingement. Am J Sports Med. 2010;38(1):114-9. http:// dx.doi.org/10.1177/0363546509346050. PMid:19966099.

49. Ellenbecker T, Roetert EP. Age specific isokinetic glenohumeral internal and external rotation strength in elite junior tennis players. J Sci Med Sport. 2003;6(1):63-70. http://dx.doi. org/10.1016/S1440-2440(03)80009-9. PMid:12801211.

50. Saccol MF, Gracitelli GC, da Silva RT, Laurino CF, Fleury AM, Andrade MS, et al. Shoulder functional ratio in elite junior tennis players. Phys Ther Sport. 2010;11(1):8-11. http://dx.doi.org/10.1016/j.ptsp.2009.11.002. PMid:20129117.

51. Johansson FR, Skillgate E, Lapauw ML, Clijmans D, Deneulin VP, Palmans T, et al. Measuring eccentric strength of the shoulder external rotators using a handheld dynamometer: reliability and validity. J Athl Train. 2015 [Epub ahead of print]. http://dx.doi.org/10.4085/1062-6050-49.3.72. PMid:25974381.

52. Ellenbecker T, Roetert EP. Age specific isokinetic glenohumeral internal and external rotation strength in elite junior tennis players. J Sci Med Sport. 2003;6(1):63-70. http://dx.doi. org/10.1016/S1440-2440(03)80009-9. PMid:12801211.

53. Andrade MS, Fleury AM, de Lira CA, Dubas JP, da Silva AC. Profile of isokinetic eccentric-to-concentric strength ratios of shoulder rotator muscles in elite female team handball players. J Sports Sci. 2010;28(7):743-9. http:// dx.doi.org/10.1080/02640411003645687. PMid:20496224.

54. Ellenbecker TS, Davies GJ. The application of isokinetics in testing and rehabilitation of the shoulder complex. J Athl Train. 2000;35(3):338-50. PMid:16558647.

55. Hébert LJ, Maltais DB, Lepage C, Saulnier J, Crête M, Perron $\mathrm{M}$. Isometric muscle strength in youth assessed by handheld dynamometry: a feasibility, reliability, and validity study. Pediatr Phys Ther. 2011;23(3):289-99. http://dx.doi. org/10.1097/PEP.0b013e318227ccff. PMid:21829128.

56. Cadogan A, Laslett M, Hing W, McNair P, Williams M. Reliability of a new hand-held dynamometer in measuring shoulder range of motion and strength. Man Ther. 2011;16(1):97-101. http://dx.doi.org/10.1016/j.math.2010.05.005. PMid:20621547.

57. Ribeiro A, Pascoal AG. Resting scapular posture in healthy overhead throwing athletes. Man Ther. 2013;18(6):547-50. http://dx.doi.org/10.1016/j.math.2013.05.010. PMid:23791560.

58. Uhl TL, Kibler WB, Gecewich B, Tripp BL. Evaluation of clinical assessment methods for scapular dyskinesis.
Arthroscopy. 2009;25(11):1240-8. http://dx.doi.org/10.1016/j. arthro.2009.06.007. PMid:19896045.

59. Oyama S, Myers JB, Wassinger CA, Daniel Ricci R, Lephart SM. Asymmetric resting scapular posture in healthy overhead athletes. J Athl Train. 2008;43(6):565-70. http:// dx.doi.org/10.4085/1062-6050-43.6.565. PMid:19030133.

60. Struyf F, Nijs J, Mottram S, Roussel NA, Cools AM, Meeusen R. Clinical assessment of the scapula: a review of the literature. Br J Sports Med. 2014;48(11):883-90. http:// dx.doi.org/10.1136/bjsports-2012-091059. PMid:22821720.

61. Cools AM, Geerooms E, Van den Berghe DF, Cambier DC, Witvrouw EE. Isokinetic scapular muscle performance in young elite gymnasts. J Athl Train. 2007;42(4):458-63. PMid:18174933.

62. Cools AM, Struyf F, De Mey K, Maenhout A, Castelein B, Cagnie B. Rehabilitation of scapular dyskinesis: from the office worker to the elite overhead athlete. Br J Sports Med. 2014;48(8):692-7. http://dx.doi.org/10.1136/ bjsports-2013-092148. PMid:23687006.

63. Michener LA, Boardman ND, Pidcoe PE, Frith AM. Scapular muscle tests in subjects with shoulder pain and functional loss: reliability and construct validity. Phys Ther. 2005;85(11):1128-38. PMid:16253043.

64. Cools AM, Dewitte V, Lanszweert F, Notebaert D, Roets A, Soetens B, et al. Rehabilitation of scapular muscle balance: which exercises to prescribe? Am J Sports Med. 2007;35(10):1744-51. http://dx.doi.org/10.1177/0363546507303560. PMid:17606671.

65. Van de Velde A, De Mey K, Maenhout A, Calders P, Cools AM. Scapular-muscle performance: two training programs in adolescent swimmers. J Athl Train. 2011;46(2):160-7. http:// dx.doi.org/10.4085/1062-6050-46.2.160. PMid:21391801.

66. Merolla G, De Santis E, Sperling JW, Campi F, Paladini P, Porcellini G. Infraspinatus strength assessment before and after scapular muscles rehabilitation in professional volleyball players with scapular dyskinesis. J Shoulder Elbow Surg. 2010;19(8):1256-64. http://dx.doi.org/10.1016/j. jse.2010.01.022. PMid:20421171.

67. De Mey K, Danneels L, Cagnie B, Cools AM. Scapular muscle rehabilitation exercises in overhead athletes with impingement symptoms: effect of a 6-week training program on muscle recruitment and functional outcome. Am J Sports Med. 2012;40(8):1906-15. http://dx.doi. org/10.1177/0363546512453297. PMid:22785606.

\section{Correspondence \\ Ann Cools \\ University Hospital Ghent \\ Department of Rehabilitation Sciences and Physiotherapy \\ De Pintelaan 185, 2B3, B9000 Gent, Belgium \\ e-mail: ann.cools@ugent.be}

